\title{
Trypanosoma cruzi Strains and Autonomic Nervous System Pathology in Experimental Chagas Disease
}

\author{
Márcia Maria de Souza, Sonia G Andrade, Aryon A Barbosa Jr, Raimunda \\ Telma Macedo Santos*, Venâncio Avancini Ferreira Alves*, \\ Zilton A Andrade ${ }^{+}$
}

\author{
Laboratório de Patologia Experimental, Centro de Pesquisas Gonçalo Moniz -FIOCRUZ, Rua Valdemar Falcão \\ 121, 40295-001 Salvador, BA, Brasil * Instituto Adolfo Lutz, Av. Dr. Arnaldo 355, 01246-902 \\ São Paulo, SP, Brasil
}

Lesions involving the sympathetic (para-vertebral ganglia) and para-sympathetic ganglia of intestines (Auerbach plexus) and heart (right atrial ganglia) were comparatively analyzed in mice infected with either of three different strain types of Trypanosoma cruzi, during acute and chronic infection, in an attempt to understand the influence of parasite strain in causing autonomic nervous system pathology. Ganglionar involvement with neuronal destruction appeared related to inflammation, which most of the times extended from neighboring adipose and cardiac, smooth and striated muscular tissues. Intraganglionic parasitism was exceptional. Inflammation involving peripheral nervous tissue exhibited a focal character and its variability in the several groups examined appeared unpredictable. Although lesions were generally more severe with the Y strain, comparative qualitative study did not allow the conclusion, under the present experimental conditions, that one strain was more pathogenic to the autonomic nervous system than others. No special tropism of the parasites from any strain toward autonomic ganglia was disclosed.

Key words: Trypanosoma cruzi - strain-types - autonomic nervous system

Geographic differences in clinical presentation of Chagas disease have been claimed by several authors and the subject discussed in specific meeting (Prata 1975), but the factors involved have not been clarified. One factor most frequently suggested concerns diversity of parasite strains. Tissue changes caused by separate Trypanosoma cruzi strains in experimental animals can indeed look quite different from one another (Andrade 1985). On the other hand, a tendency for a given T. cruzi strain to predominate in certain endemic areas has already been detected (Andrade 1974). Clinically, the most striking geographic variation concerns the prevalence of the digestive forms of Chagas disease. While Chagas myocardiopathy practically maintains its same clinical presentation everywhere, chagasic megaesophagus prodominates in Central Brazil, is relatively rare in other endemic regions and is practically non-existent in Central America (Suarez 1967, Blandon et al. 1969, Rezende \& Luquetti 1994). These facts suggest that the autonomic nervous system may be differently compromised by Chagas disease. One can assume that a strain that predominantly parasitizes the

${ }^{+}$Corresponding author. Fax: 55-71-359.4292

Received 18 August 1995

Accepted 15 December 1995 structures of the autonomic nervous system, is prone to damage such system. Tissue tropism is an important biological characteristic of a strain, and is one of the parameters currently utilized for biological strain differentiation (Andrade 1985). Therefore, the study of the relationship between T. cruzi strains and autonomic nervous system involvement may help clarify questions related to differences in geographic manifestations of Chagas disease.

The adoption of the strain-type concept facilitated the selection of strains to be compared. The classification allows $T$. cruzi strains to be divided into three groups of "strain types". This was initially made on the basis of common morphological and biological characteristics (Andrade 1974, 1985), but there is correlation with isoenzymic analysis (Andrade et al. 1983).

The present investigation is a comparative histopathologic and immuno-histochemical study of the sympathetic and parasympathetic autonomic nervous system lesions produced in mice during acute and chronic infection by three different $T$. cruzi strain types.

\section{MATERIALS AND METHODS}

Animals - Outbred Swiss mice of both sexes, 15-18g initial weight, were used. They were kept in plastic cages with water and food (a balanced commercial pelleted diet) ad libitum. 
T. cruzi strains - Mice were infected with either one of the following T. cruzi strains: Y, 21SF and Colombian strains, which are the prototypes of the three different types of $T$. cruzi strains described by Andrade (1974, 1985),

Briefly, Y strain (Silva \& Nussenzweig 1953), Type I : characterized by a rapid course of infection in mice, high levels of parasitemia, and mortality around the 11th and 13th day of infection, with predominance of slender forms in peripheral blood and macrophagotropism during the acute phase of infection, zymodeme Z2b; 21SF strain (Andrade 1974); Type II, increasing parasitemia from the 12th to the 20th day of infection, low rate of mortality, predominance of broad forms of the parasites and myocardiotropism, zymodeme Z2; Colombian strain (Federici et al. 1964); Type III, slow development of parasitemia, with the highest levels around 25 to 30 days after inoculation, low mortality and predominance of parasitism in skeletal muscle, zymodeme Z1.

Experimental groups - Group I - Nineteen mice were infected with 59,940 blood forms of T. cruzi Y strain obtained from infected mice. Parasitemia levels were daily evaluated in peripheral blood by direct microscopic examination. Five animals were killed during acute infection (11 days); the surviving mice were treated with low doses of Benznidazole ( $1 \mathrm{mg} /$ day during 3 days) for supression of parasitemia. Fourteen of them were killed 90 days after infection. Group II - Eleven mice were infected with the 21SF $T$. cruzi strain. Five of them, infected with 105,300 blood forms, were sacrificed during the acute phase of the infection (21 days). Six animals were in the chronic phase, survivors of different groups of infection. They had received different inocula which varied from 75,000 to 197,000 blood forms. Duration of infection for this group varied from 12 to 24 months. Group III - Ten mice infected with the Colombian strain of $T$. cruzi. Five animals were inoculated with 112,300 blood forms and were killed in the acute phase of infection ( 30 - 40 days). Five chronicaly infected mice that have been inoculated with different inocula varying from 28,000 to 180,000 blood forms were sacrified from 10 to 12 months after infection. Group IV - Control groups: five intact young mice were used as controls of the acutely infected mice. Five intact adult mice, weighing 25 to $30 \mathrm{~g}$ were used as controls for the chronically infected mice.

Histopathology - Three tissue areas were selectively fixed in $\mathrm{pH} 7.2$ phosphate buffered formalin and/or Bouin's fluid: the heart, the ileo-cecal area of the intestines and the tissues around the vertebral column from the cervical to the dorsolumbar region. The first two areas as representa- tive for the parasympathetic system, and the third for the sympathetic system.

The heart was fixed in totum and afterwards divided into two equal parts by a longitudinal section through the lateral border, reaching the middle of the atrial and ventricular septa. The two parts were embedded in a single paraffin block with the sectioned areas facing the microtome cutting face.

The intestines were opened through the mesenteric border, washed gently, distended in a cardboard and then fixed in formalin. Three to four longitudinal strips of about $1.5 \mathrm{~cm}$ long, containing the ileo-cecal transition in its middle, were taken from the fixed specimens and embedded in a single paraffin block.

As for the tissues in the vicinity of the vertebral column, they were taken from the fixed animal carcass by means of two longitudinal sections made $0.5 \mathrm{~cm}$ away from the vertebral lateral apophises on each side, and two horizontal cuts, one superior (cervical region) and one inferior (lumbar region). The tissue, having the vertebra with the spinal cord in its center, were cut into three or four blocks that were decalcified in EDTA and embedded in paraffin.

All the paraffin blocks were submitted to a step sectioning method by which five micrometer-thick sections were taken at least $30 \mu \mathrm{m}$ apart, to avoid the presence of the same neuron in more than one section. The sections were routinely stained with hematoxylin and eosin and, ocasionally, with the PAS-Schiff, and the sirius-red for collagen.

Immuno-histochemistry - Paraffin sections of heart tissue fixed in Bouin's fluid were submitted to an avidin-biotin-peroxidase technique. Rabbit anti-enolase serum (Dako, Copenhagen, Denmark, diluted 1:1,000) and rabbit anti-T. cruzi serum (kindly provided by Dr Ivan Mota, Instituto Butantã, São Paulo, Brazil, diluted 1:20,000) were used as primary antibodies. Secondary antibody was a biotinylated goat anti-rabbit IgG, 1:2,000. Localization of the reaction was by means of avidin-biotin-peroxidase complex (Vector), 1:1,000, followed by $60 \mathrm{mg} \%$ DAB (Sigma, St. Louis, USA) as chromogen. Slides were counterstained with hematoxylin.

\section{RESULTS}

General findings - Changes in the autonomic nervous system consisted of peri and intraganglionar infiltration by mononuclear leukocytes, congestion, edema and, rarely, the presence of $T$. cruzi amastigotes within the ganglionic capsular cells during acute infection (Fig. 1). In the presence of inflammation the neurones presented cytoplasmic swelling, vacuolization, decreased basophilia, nuclear condensation, cariorhexis and cellular loss (dropping-out). Neuronophagia and 
proliferation of satelite cells, interstitial edema with dissociation of nerve fibers within the ganglion were sometimes noted. These changes coincided with the presence of inflammatory cells within and/ or in close proximity to the ganglion. No evident alterations of neurones were found in the absence of inflammation, even in animals chronically infected with T. cruzi. Any infected animal presented inflamed ganglion with altered neurones as well as normal looking, non-inflamed ones. Changes were more intense and more frequent during acute infection. The proportion of inflamed ganglia varied from case to case within the same group, apparently more so than from one group to another. Parasites were rarely found within the ganglia, even when an immunohistochemistry technique was utilized. No parasites were ever seen within the nervous structures during the chronic stage of the infection. The immunohistochemistry technique with anti-enolase antibodies did selectively mark neurones and nerve fibers of the autonomic system, but did not add any further information already not observed with the routinely stained slides (Fig. 2). No changes were detected in the autonomic nervous system of either young or old non-infected controls. Only one old mouse presented focal arteritis in sections from intestines and skeletal muscles.
T. cruzi $Y$ strain - The main characteristic during acute infection was the parasitism and inflammation of the fatty tissue, especially at the base of the heart and in the retroperitoneum. Some ganglia emeshed in adipose tissue near the heart and paravertebral muscles were particularly involved, apparently by the extension of the neighboring inflammatory changes. The degree of inflammation within the heart (myocarditis) and intestines was mild to moderate during acute and chronic infection (Fig. 3). During the chronic phase the main changes were found in the paravertebral tissues, when myositis, paniculitis and vasculitis were prominent. Ganglionitis in this area was also marked and destruction sometimes involved approximately 20 to $60 \%$ of the neuronal tissue, including many neurones and nerves (Fig. 4). Sympathetic ganglia located within the vertebral canal, away from inflammatory changes, were preserved, while those outside, near inflamed muscle and adipose tissue were severely damaged. Vascular lesions consisted of focal hyalinization of arterial walls, peri-vascular infiltration of mononuclear leukocytes and, rarely, fibrinous thrombosis. These vascular changes were seen in intestines and, more rarely and less markedly, in the heart.

T. cruzi 21SF strain - Myocarditis was the principal finding during acute infection and the

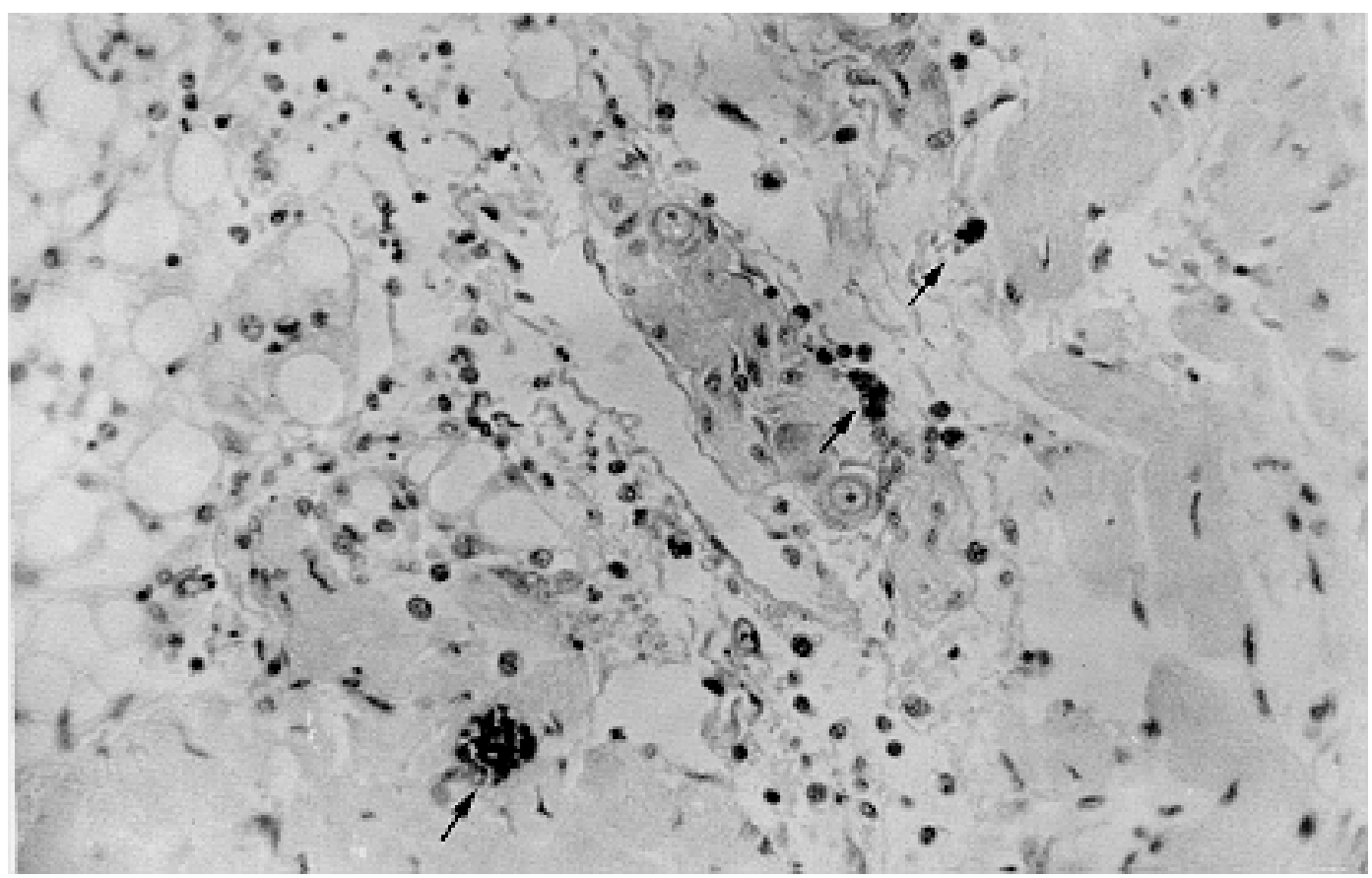

Fig. 1: presence of intracellular Trypanosoma cruzi amastigotes in the proximities of a cardiac parassympathetic nervous ganglium (arrows). A few inflammatory cells are seen within the ganglium, sometimes encircling the neurones. Acute infection by Y strain. Immuno-histochemistry. Avidin-biotin peroxidase plus anti-T. cruzi antibodies, counterstained with hematoxylin, X 200. 


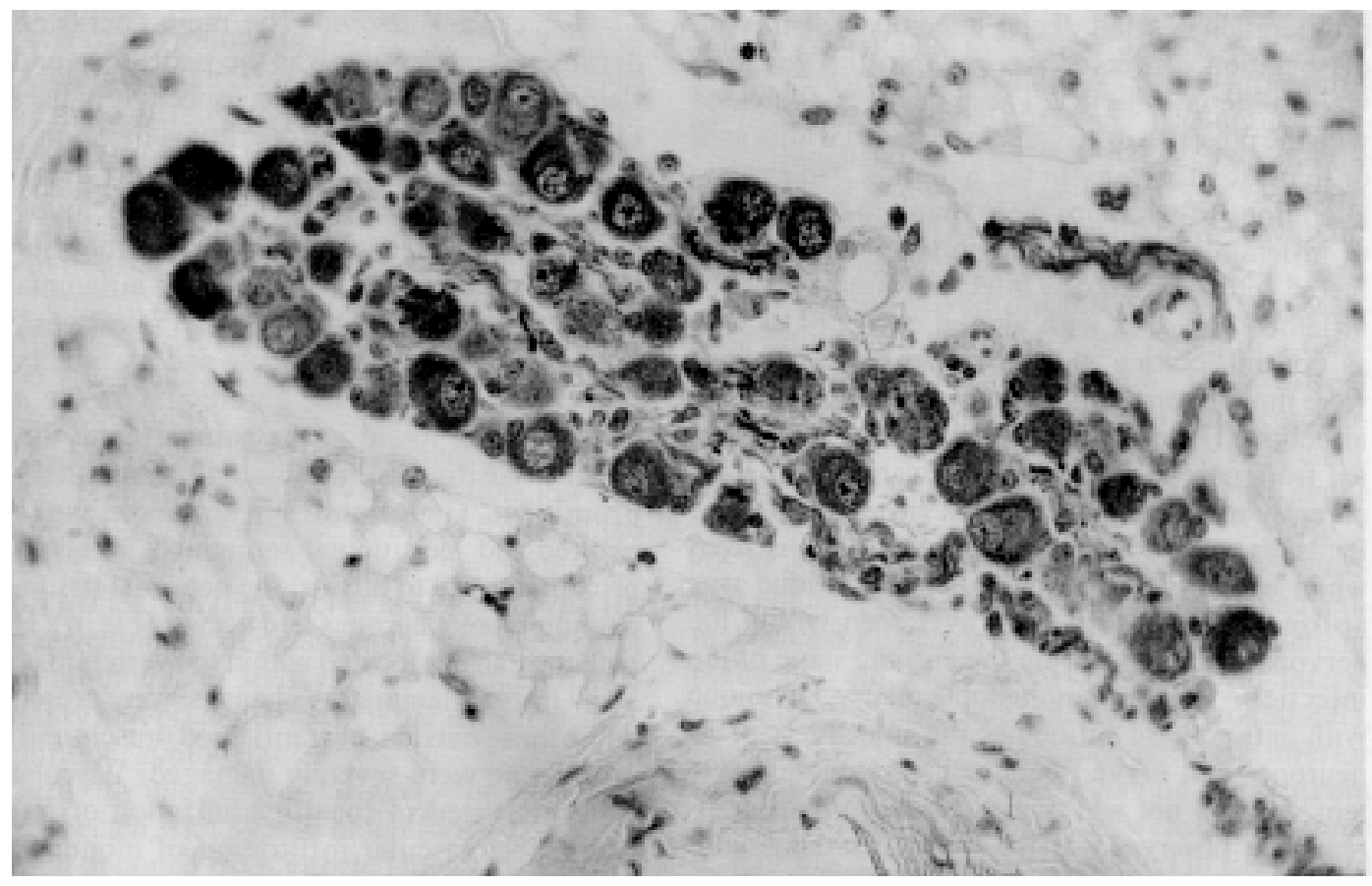

Fig. 2: parasympathetic cardiac ganglium located in the sub-epicardial adipose tissue showing chronic inflammation, interstitial fibrosis, neuronal dissociation and damage, with loss of a few neurones. Chronic infection with Trypanosoma cruzi $21 \mathrm{SF}$ strain. Immuno-histochemical staining for enolase. X400.

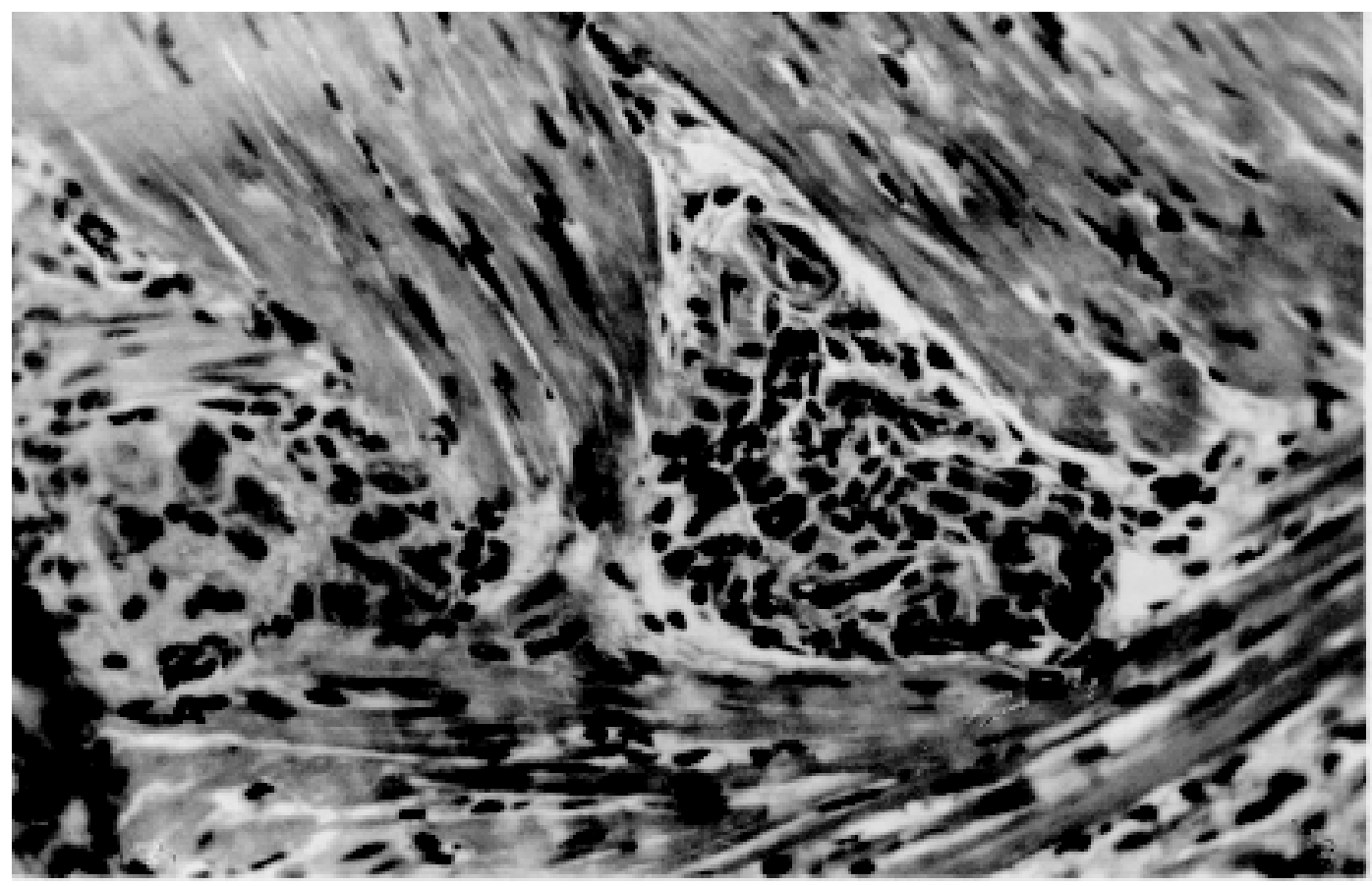

Fig. 3: muscular layer of the colon during chronic Trypanosoma cruzi (Y strain) infection. Focal lesions involving two portions of the Auerbach plexus. Neurones are not identified in the one exhibiting more severe inflammation (B), while some dissociated ones are present in A. Hematoxylin-eosin, X400. 


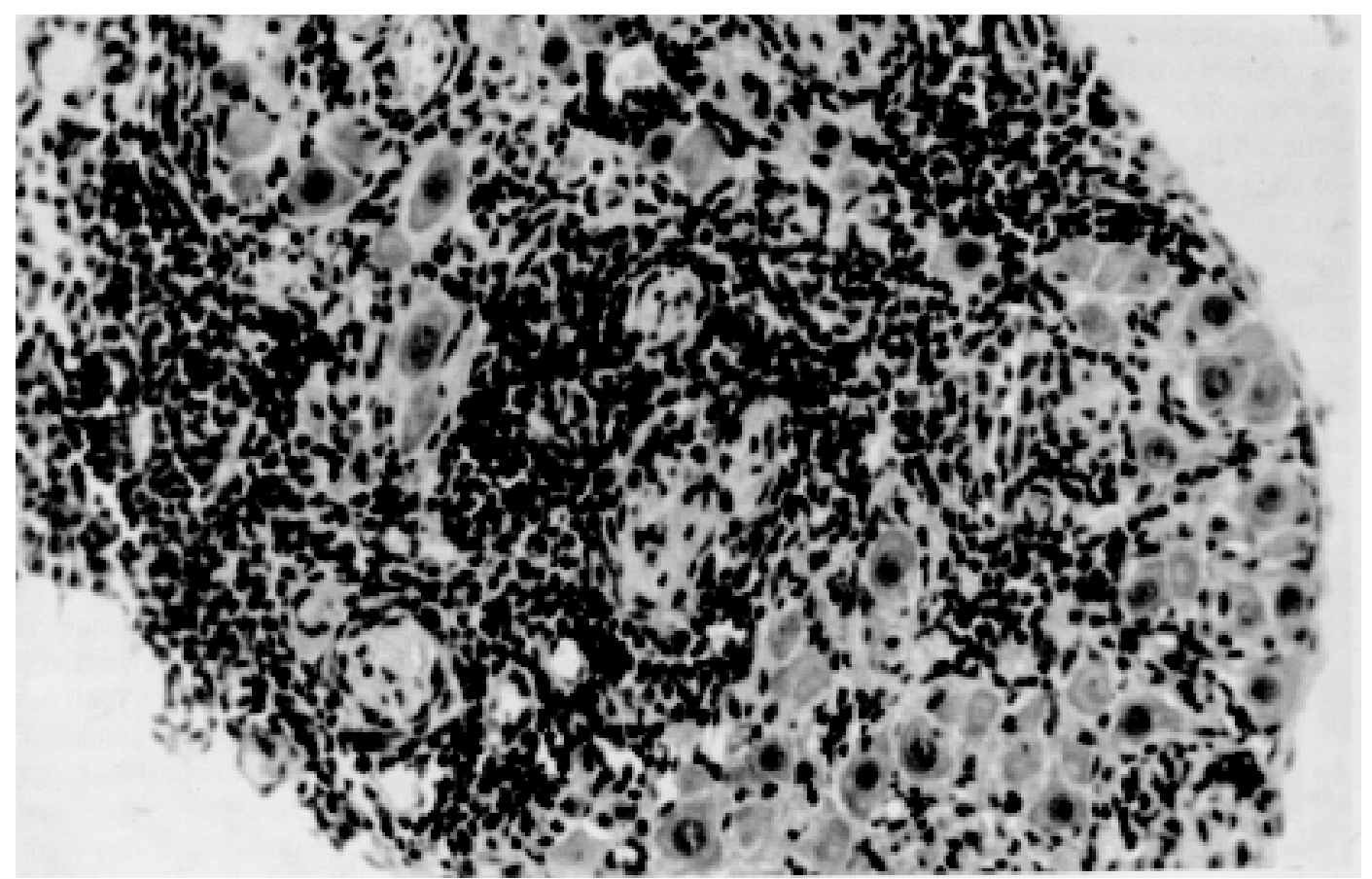

Fig. 4: paravertebral sympathetic ganglium with chronic inflammation and severe neuronal loss, as seen in a mouse with chronic infection due to 21-SF strain of Trypanosoma cruzi. Hematoxylin -eosin, X400.

inflammation appeared to be out of proportion to the relatively few parasites found within myocites. Involvement of cardiac autonomic ganglia was frequent. However, the inflammatory infiltrates were seen to dissociate the neurones, but only mild degenerative changes were present in them (Fig. 5). Inflammatory lesions were also seen in the muscular layer of the intestine, with infiltration of the Auerbach plexus, but here again neuronal changes were minimal. Focal inflammatory lesions in paravertebral tissues were of a moderate degree and involved solely the skeletal muscles. Chronic infection was caracterized by mild multifocal myocarditis, mild intestinal myositis and conspicous vasculitis, mainly seen in paravertebral tissues, occurring in four of the six animals examined. It was similar to that seen in the previous group, but more severe, with hyaline necrosis of the vascular walls frequently present.

T. cruzi Colombian strain - Moderate myocarditis and myositis were the main changes during acute infection. Parasites were scarce, but sometimes formed large elongated collections of amastigotes within skeletal muscle. Extension of the inflammatory infiltrate into de nervous ganglia occurred in a few instances. Even then, neuronal lesions were mild, the neurones appearing only dissociated by the infiltrating mononuclear leukocytes. The grey adipose tissue presented with focal inflammation. This was also observed in chronic infection, when focal paniculitis and myositis conspicously appeared in the paravertebral tissues. Inflammation of the muscular coats of the intestines and involvement of the Auerbach plexus occurred frequently, but destruction of nervous tissue was relatively mild (Fig. 6). Focal vasculitis, with hyaline necrosis and perivascular inflammation, was seen in all but one case, especially in the paravertebral tissue and intestines.

\section{DISCUSSION}

The very concept of $T$. cruzi strains has been challenged following cloning studies (Postan et al. 1983), but the fact is that isolates of the parasite tend to reveal groups with common morpho-biological features (Andrade 1974), iso-enzimatic characteristics (Miles et al. 1980) and kinetoplast DNA restriction maps (Morel et al. 1980, Tibayrenc et al. 1986), which correlates with geographic procedence, immunological responses, clinical data and susceptibility to chemotherapy (Andrade et al. 1985).

By infecting mice with different strain types and observing the lesions involving the sympathetic and parasympathetic autonomic nervous system, no special tropism of any strain toward the auto- 


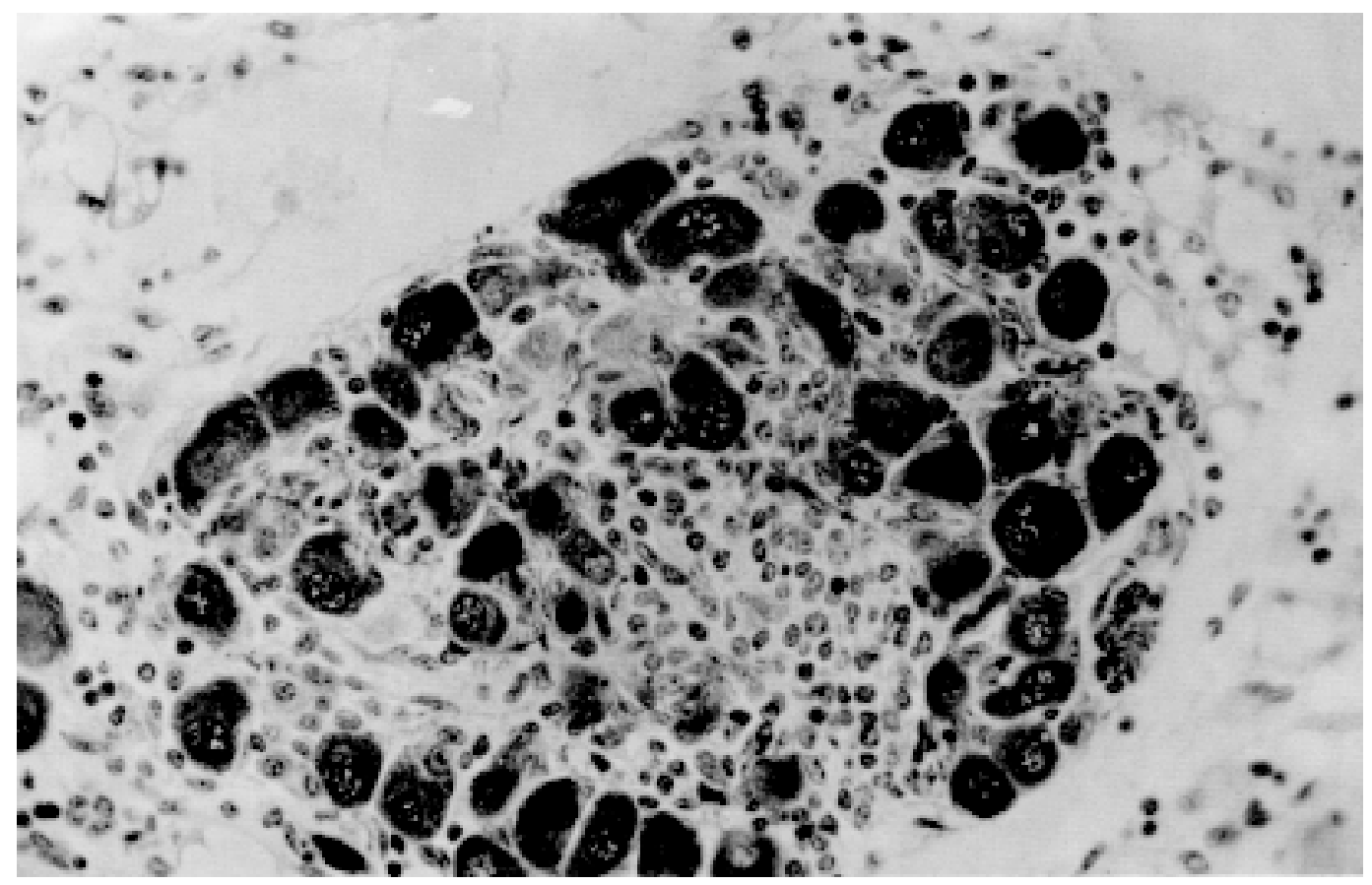

Fig. 5: dorsal sympathetic ganglium showing severe inflammation and neuronal destruction during chronic infection caused by Trypanosoma cruzi Y-strain. Hematoxylin-eosin, X400.

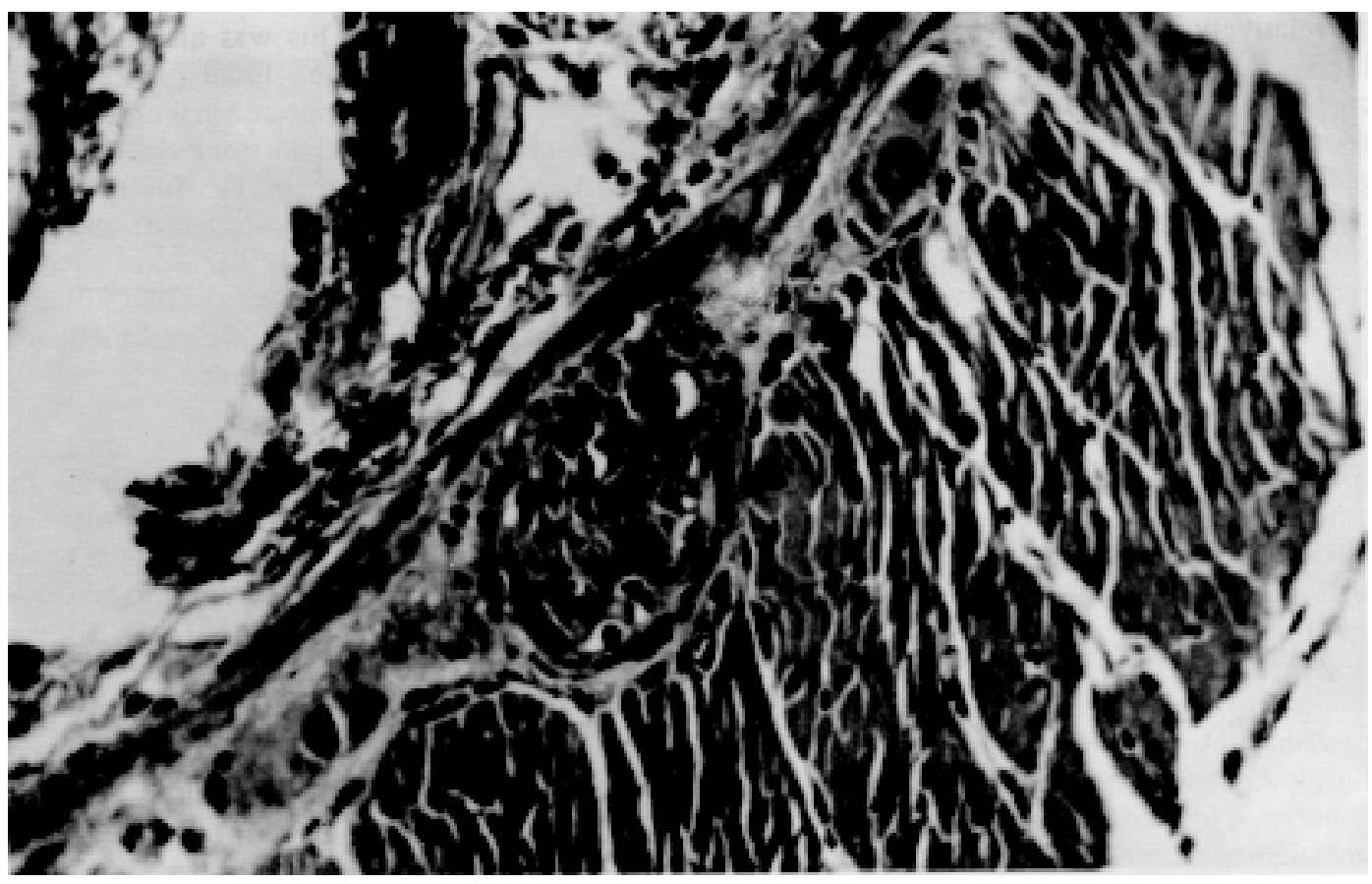

Fig. 6: muscular layer of the small intestine presenting focal inflammatory lesion involving the Auerbach plexus with neuronal destruction. Nearby non-inflamed neurones show normal-looking histological appearance. Acute infection with Trypanosoma cruzi Colombian strain. Hematoxylin-eosin, X160. 
nomic nervous system was observed, although differential tropism to other organs as expected for each strain-type has been confirmed. Neuronal destruction correlated well with inflammation. Non-inflamed ganglion and even a non-inflamed part of an inflamed ganglion presented neuronal structures similar to those seen in non-infected controls. The relationship of inflammation and neuronal damage has been demonstrated experimentally in corticoid-treated mice, when suppression of inflammation abolished neuronal destruction (Andrade \& Andrade 1968a). Correlation of inflammation and neuronal injury has also been emphasized by others (Tafuri \& Raso, 1962, Tafuri \& Brener 1966, Lopes \& Tafuri 1983, Wong et al. 1992). During acute infection inflammation and tissue parasitism showed good correlation, although $21 \mathrm{SF}$ strain lesions exhibited more inflammation than parasites. However, in chronic infection parasites were scarce and difficult to be demonstrated in tissue sections while focal inflammation was sometimes marked. The positive correlation between inflammation and neuronal lesions continued to exist, despite the absence of demonstrable parasitism by histological and immunohistochemical methods. Although parasites were rarely found within nervous ganglia, inflammation appeared most of the times as an extension from muscular and adipose tissue changes, where parasites were more frequently found. Tropism of the parasites towards adipose tissue was evident in acute lesions due to the $\mathrm{Y}$ strain. In such case the main cell type involved by parasitism was the adipocyte itself (Andrade \& Rocha 1995).

Tafuri and Brener (1966) noted that Y strain caused more severe lesions in the autonomic nervous tissue of mice as compared to other strains. As now observed, both in acute and chronic infections, inflammatory lesions caused by the $\mathrm{Y}$ strain were more destructive to the neuronal tissue than those caused by the other two strain-types, where inflammation caused more dissociation of the neurones rather than destruction. However, due to the unpredictiveness of the inflammatory lesions to reach the autonomic ganglia, it was not possible to conclude that one strain was more pathogenic to the system than the other. Clear-cut fibrotic (cicatricial) lesions, such as those seen in human material (Lopes \& Tafuri 1983, Andrade 1994) were not observed in the autonomic nervous system in the present study. As a matter of fact, fibrosis was not an outstanding change in any of the animals, except for mild to moderate atrial interstitial fibrosis accompaning chronic myocarditis.

The fact that lesions involving the autonomic nervous ganglia have a focal rather than a diffuse distribution points toward a direct parasite-related pathogenesis. This would indicate the importance of the acute stage of the infection, when parasitism is maximum, for the involvement of the autonomic nervous system in Chagas disease. The focal ganglionic lesions also differ from those diffuse cardiac inflammatory lesions seen in acute and chronic active Chagas disease and for which immunologically-related mechanisms have been postulated (Sadigursky et al. 1990). Therefore, the cardiac and the digestive forms of Chagas disease may indeed depend on different pathogenesis, as previously suggested (Andrade 1983, Andrade \& Andrade 1992).

Focal arteritis was a conspicous finding in several mice chronically infected by $T$. cruzi. As noted before, focal necrotizing arteritis sometimes occurs spontaneously in old mice, but apparently that can be pontentiated during chronic T. cruzi infection (Andrade \& Andrade 1968b).

A quantitative evaluation of the lesions in the autonomic nervous system would seem more appropriate than this qualitative study, but it is not a simple task. Distribuition of nervous ganglia is sparce and unpredictable in the heart. The number of neurones vary considerable in different areas and in different ganglia, especially in several zones of the Auerbach plexi of the intestines. There are differences in size and distribuition of the ganglia in the sympathetic sector. A critical appraisal of the disparate results obtained by methods of counting the number of neurones in histological sections in cases of Chagas disease has been presented (Oliveira 1985). Computerizable morphometric methods may be more appropriate and these are worth being considered for future studies.

\section{REFERENCES}

Andrade SG 1974. Caracterização de cepas do Trypanosoma cruzi isoladas do Recôncavo Baiano (Contribuição para o estudo da patologia geral da doença de Chagas em nosso meio). Rev Pat Trop 3: $65-121$.

Andrade SG 1985. Morphological and behavioural characterization of Trypanosoma cruzi strains. Rev Soc Bras Med Trop 18 (Supl. 1): 39-46.

Andrade SG, Andrade ZA 1968a. Doença de Chagas e alterações neuronais do plexo de Auerbach (Estudo experimental em camundongos) Rev Inst Med Trop $S$ Paulo 8: 219-224.

Andrade SG, Andrade ZA 1968b. Patologia da doença de Chagas experimental de longa duração. Rev Inst Med Trop S Paulo 10: 180-187.

Andrade SG, Magalhães JB, Pontes AL 1985. Evaluation of chemotherapy with benznidazole and nifurtimox in mice infected with Trypanosoma cruzi strains of different types. Bull Wrld Hlth Org 63: 721-726.

Andrade V, Brodskyn C, Andrade SG 1983. Correla- 
tion between isoenzyme pattern and biological behaviour of different strains of Trypanosoma cruzi. Trans R Soc Trop Med Hyg 77: 796-799.

Andrade ZA 1983. Mechanisms of myocardial damage in Trypanosoma cruzi infection. CIBA Foundation Symposium 99: 214-233.

Andrade ZA 1994. Pathology of the autonomic nervous system in Chagas' disease. In Chagas'disease and the nervous system. PAHO Sci Publ 547:212221.

Andrade ZA, Andrade SG 1992. Pathological findings in Chagas' disease. In RJ Madoery, C Madoery, MI Cámera (eds) Actualizaciones en la enfermedad de Chagas Congreso Nacional de Medicina, Cordoba, Argentina.

Andrade ZA, Rocha Silva HR 1995. Parasitism of adipocytes by Trypanosoma cruzi. Mem Inst Oswaldo Cruz 90: 521-522.

Blandon R, Guevara JF, Johnson CM 1969 Tránsito esofágico en pacientes con enfermedad de Chagas en Panamá. Arq Gastroenterol 6: 189-196.

Frederici EE, Abelmann WH, Neva FA 1964. Chronic and progressive myocarditis and myositis in $\mathrm{C} 3 \mathrm{H}$ mice infected with Trypanosoma cruzi. Am J Trop Med Hyg 13: 272-280.

Lopes ER, Tafuri WL 1983. Involvement of the autonomic nervous system in Chagas heart disease. Rev Soc Bras Med Trop 16: 206-212.

Miles MA, Lanham SM, Souza AA, Póvoa M 1980. Further enzymic characters of Trypanosoma cruzi. Trans R Soc Trop Med Hyg 74: 221-223.

Morel CM, Chiari E, Camargo EP, Mattei DM, Romanha AJ, Simpson L 1980. Strains and clones of Trypanosoma cruzi can be characterized by pattern of restriction endonuclease production of kinetoplast DNA minicircles. Proc Natl Acd Sci USA 77: 6810-6814.

Oliveira JSM 1985. A natural human model of intrinsic heart nervous system denervation: Chagas' cardiopathy. Am Heart J 110: 1092-1098.

Postan M, Dvorak JA, Daniel JP 1983. Studies of Trypanosoma cruzi clones in inbred mice. A comparison of the course of infection of $\mathrm{C} 3 \mathrm{H} / \mathrm{HEN}$ mice with two clones isolated from a common source. Am J Trop Med Hyg 32: 479-506.

Prata A 1975. Reunião sobre diferenças geográficas na Doença de Chagas. Brasília 4-5 August.

Rezende JM, Luquetti AO 1994. Chagasic Megavisceras. In Chagas' disease and the nervous system. PAHO Sci Publ 547: 149-171.

Sadigursky M, von Kreuter BF, Pei-Ying Ling BS, Santos-Buch CA 1990. Association of elevated antisarcolema, anti-idiotype antibody levels with the clinical and pathological expression of chronic Chagas' myocarditis. Circulation 80: 1267-1276.

Silva LHP, Nussenzweig V 1953. Sobre uma cepa do T. cruzi altamente virulenta para o camundongo branco. Folia Clin Biol 20: 191-208.

Suarez JA 1967. Los gánglios neurovegetativos intracardiácos en la miocarditis chagásica. Tesis, Caracas, Venezuela. 82pp.

Tafuri WL, Brener Z 1966. Lesões do sistema nervoso autônomo do camundongo albino na tripanosomíase cruzi experimental, na fase aguda. O Hospital 69: 371-383.

Tafuri WL, Raso P 1962. Lesões do sistema nervoso autônomo do camundongo albino na tripanosomíase. O Hospital 62: 1324-1342.

Tibayrenc M, Ward P, Moya A, Ayala JF 1986. Natural populations of Trypanosoma cruzi; the agent of Chagas' disease. Proc Nat Acd Sc USA 83: 115119.

Wong WC, Tan CK, Singh M, Yick TY 1992. Ultrastructure of murine cardiac ganglia in experimental Chagas' disease. Histol Histopath 7: 371-378. 